\title{
An Analysis of Tourists' Willingness to Accept under Forced Consumption from Travel Agencies
}

\author{
Jian-Hua WEI*, Meng DING \\ College of Tourism, Jiujiang University Jiangxi Province, China \\ No.551 Qianjin East Avenue Jiujiang, 332005 \\ Email: wjh30330@163.com
}

Keywords: Forced consumption, Negative experience, Travel agencies, WTA.

\begin{abstract}
The phenomenon of forced consumption by travel agencies and tour guides is endless. This not only has a great impact on the reputation of tourism destinations, but also reduces the tourists experience utility. The purpose of this paper is to study the influence of the forced consumption of travel agencies on the tourists' experience utility. Based on the willingness to accept (WTA) method, we investigated the price of tourists willing to accept forced consumption or compulsive consumption under certain circumstances, and the price of willingness to accept compensation. It helps the relevant departments to solve such negative events, and provides data for reference, so as to improve the tourists experience in the process of travel.
\end{abstract}

\section{Introduction}

According to a survey conducted by the China Youth Daily Social Survey Center, a combined questionnaire survey shows that $84.7 \%$ of respondents travel by a agencies, and $78.6 \%$ of respondents had "enforced shopping" when they or their neighbors travelled with the group. In addition, the travel group's inflexible behavior includes "zero tour fee" (63.2\%), discounted or shrunk service items (55.5\%), The shopping is the most basic routine, and low price is the marketing strategy that travel agencies compete with each other.

Why the "low-cost group" forced shopping so hardly to be prohibited? Tourism is an intangible and experiential product. People have no idea what their quality is before they are consumed. Travel agencies face competitive pressure from homogeneous rivals. It is impossible to open up the gap by improving the quality of products and services in a short period of time, resulting in a vicious price war . The improper treatment of tourism negative events and the policy of tackling key problems will significantly affect the life cycle and tourism demand of tourism destinations, and further hinder the healthy and sustainable development of tourism[1,2]. Based on the above-mentioned problem of tourism market, it is of great practical significance to evaluate the degree of infringement on consumer's experience utility by compulsory consumption.

Tourism experience research began in the 1960s. Boorstin (1961) first put the research perspective on the travel experience and interpreted the travel experience as a popular consumer behavior[3]. Hughes (1991) proposed the theory of expected value. He believes that when the experience of tourists is greater than the expectations of tourists, the satisfaction of tourists is higher and the utility is greater. Jackson (1996) used positive experiences and negative experiences to describe the experience of tourists[4]. Enrique Bigne (2001) started from the overall satisfaction of tourists after the consumption, and proposed that experiencing the quality of products affects the satisfaction of tourists and whether they purchase again[5]. The image of tourism products is also satisfied with the satisfaction of tourists, whether they are satisfied, and recommend them to others. And experience product quality has a great influence. Iii (2001) finds that different levels of service compensation have different effects on satisfaction, purchase intention, and the spread of positive word-of-mouth[6].Moderate-to-high-level service compensation significantly improves the satisfaction, purchase intentions, and positive word-of-mouth. The effect of service remediation is also influenced by internal factors of consumers. It mainly includes factors such as fair perception, 
emotion, customer identification, and participation [7]. There is a close relationship between fairness and satisfaction with customer remedies [8,9].

\section{Date and Mothed}

The data in this study was published through online questionnaire and 130 questionnaires were eventually collected. The questionnaire is divided into two major parts: The first part is mainly to understand the respondents' perceptions and attitudes of forced consumption in the tourism process and the respondents' perceptions of compulsory consumption; The second part is to understand through a real situation. Respondents to mandatory consumption and willingness to accept (WTA). Forced or induced consumption is frequent to take you to shopping, shopping time is longer than travel time, but you can choose not to shop. Although it did not cost any money, it wasted a lot of time and affected the travel experience, so this part is actually a compensation of time and cost. The third part is the survey of respondents' personal information, including some social attributes and backgrounds, such as the age, gender, family income, occupation, and education level of respondents.

Willingness to accept (WTA) is measured by constructing a hypothetical market for environmental goods to measure the loss of conditional goods. Changes in welfare. Essentially, it simulates the market to reveal people's willingness to accept (WTA) for environmental or service degradation. Its core is to directly investigate people's desire to pay for environmental products, and to express the economic value of environmental products with the desire to pay ${ }^{[10]}$. WTA is not based on observable or predictable market behavior but on the respondents' answers. The method can be briefly described as follows: From the perspective of consumers, under a series of hypothetical questions, consumers' preferences for public goods and services, such as resources and environment, are revealed through surveys, questionnaires, and tenders. WTA refers to the minimum income compensation that the respondent is willing to accept in the face of the loss of the intended environmental quality, and is a higher tool for the compensation of the willingness of the strategic tourists.

\section{Analysis Results}

This paper analyzes the willingness compensation under the attitude of tourists' forced consumption using the WTA method. The tourists' willingness compensation is mainly calculated from two aspects. One method is calculated as a percentage of the amount of forced consumption, and another is calculated as consumption time. Because the conditions of willingness compensation are uncertain, the willingness to accept is different. For example, tourists are forced to consume 300 yuan and 3,000 are forced to consume because the compensation for intention is different, so this calculation is based on the amount of forced consumption. Another kind is forced or induced consumption is frequent shopping, shopping time is more than travel time. However, in this case, tourists can choose not to purchase. Although there is no consumption, they waste a lot of time and affect the travel experience. Therefore, this part is actually the compensation of time and cost. For people with higher income and higher status, the time cost is relatively high. The calculated result of willingness to calculate the amount of forced consumption is shown in Table 1 below.

If tourists does experience a forced consumption or consumption trap, the amount of compensation (according to the amount of forced consumption) that visitors are willing to accept under the attitude of forced consumption, $34.62 \%$ of people said that they are willing to accept the amount of compensation for forced consumption of $100 \%, 16.92 \%$ of the respondents are willing to accept the compensation amount is $50 \%$ of the amount of forced consumption. Recipients are willing to accept the compensation mainly concentrated in the forced consumption of $50 \%$ and $100 \%$, while others are less. 
Table 1. The WTA under Consumption Compenstion

\begin{tabular}{|l|l|ll|}
\hline Consumption compensation & Frequency & Ratio & $10.77 \%$ \\
\hline $10 \%$ & 14 & & $10 \%$ \\
\hline $20 \%$ & 13 & $9.23 \%$ \\
\hline $30 \%$ & 12 & $1.08 \%$ \\
\hline $40 \%$ & 4 & $16.92 \%$ \\
\hline $50 \%$ & 22 & $1.08 \%$ \\
\hline $60 \%$ & 4 & $1.08 \%$ \\
\hline $70 \%$ & 4 & $1.92 \%$ \\
\hline $80 \%$ & 9 & $1.31 \%$ \\
\hline $90 \%$ & 3 & $14.62 \%$ \\
\hline $100 \%$ & 45 & & \\
\hline
\end{tabular}

Table 2. The WTA under Time Compenstion

\begin{tabular}{|l|l|l|}
\hline Hourly compensation & Frequency & Ratio \\
\hline $50 \mathrm{RMB}$ & 20 & $15.38 \%$ \\
\hline $100 \mathrm{RMB}$ & 44 & $33.85 \%$ \\
\hline $200 \mathrm{RMB}$ & 26 & $20 \%$ \\
\hline $300 \mathrm{RMB}$ & 12 & $9.23 \%$ \\
\hline $400 \mathrm{RMB}$ & 6 & $4.62 \%$ \\
\hline $500 \mathrm{RMB}$ & 22 & $16.92 \%$ \\
\hline
\end{tabular}

As the results of Table 2 show, if the hourly calculation is based on the consumption time, the compensation for 100 yuan, 200 yuan, and 500 yuan per hour is the majority, among which the compensation for 100 yuan per hour is the high est, accounting for $33.85 \%$ of the total. The distribution of compensation methods is shown in Figure 4-3. $71.54 \%$ of the people chose cash compensation, followed by deductions of tour fare. The respondents did not accept the compensation in kind, but only accounted for 3.08\%. It shows that people prefer the form of cash compensation, and the current compensation method is also the most effective. In addition, due to individual differences, some tourists are willing to accept compensation when they are forced to spend, but some tourists are reluctant to accept compensation, $54.62 \%$ of people expressed that they want to handle serious consumer events, do not want compensation, 37.69\% The person said compensation could not solve the problem. People still hope that the phenomenon of compulsory consumption can be contained, and relevant departments can seriously handle it to reduce the occurrence of such incidents. After a forced consumption event occurs, it will also have a certain impact on the travel plans of tourists. Survey shows that $39.23 \%$ of people said that after the event will reduce the number of acquisitions; $20 \%$ of people will go to the accident site to consider when there is no place to go; $25.38 \%$ of people will never go to the site of the incident. A small number of people said that they would postpone their travel plans. A very small number of people said they still want to go without any influence. The occurrence of forced consumption events has a great impact on the location of the incident, which affects the travel plans of tourists and has a great negative impact on the incident, and to a certain extent, it also reduces the number of trips to the accident site 


\section{Conclusions}

In this paper, the phenomenon of forced consumption is studied through the willingness compensation method. Through the analysis of the questionnaire survey data, the respondents' attitudes to forced or induced consumption and the corresponding behavior research are studied. According to surveys, the respondents believe that the current forced or induced consumption of travel agencies is relatively common, and this kind of incident is still relatively attracting people's attention. Such forced consumption events can also cause people's resentment and resistance, thus causing certain negative impact on the event tourism and affecting people's travel plans. When forced or induced consumption occurs under the compulsive consumption attitude, people's willingness to pay is higher. Under the attitude of accepting forced consumption, there are two methods of analysis of willingness to compensate: one is calculated by amount, and the other is calculated by time. In terms of consumption, most people want full compensation. For people with higher time costs, they want to spend less time. Therefore, it is urgent to deal with the phenomenon of forced consumption. This not only affects the tourist experience and effectiveness of tourists, but also has a certain impact on the destination.

\section{Acknowledgement}

The authors greatly acknowledge the financial support by the National Natural Science Foundation (71640023) and Department of Education, Jiangxi Provincial government, China.(GJJ161091)

\section{References}

[1] Albaladejo I. P. Nonconstant reputation effect in a dynamic tourism demand model for Spain[J]. Tourism Management, 2016:132-139.

[2] Yoná S. D., Júlia M. L., Paula C. R., et al. Tourism experience, events and public policies[J]. Annals of Tourism Research, 2014, 46(2):181-184.

[3] Boorstin D J. The image : a guide to pseudo-events in America[M]. Vintage Books, 1961.

[4] Jackson M S, White G N, Schmierer C L. Tourism experiences within an attributional framework.[J]. Annals of Tourism Research, 1996, 23(4):798-810.

[5] J.Enrique Bigné, M.Isabel Sánchez, Javier Sánchez. Tourism image, evaluation variables and after purchase behaviour: inter-relationship[J]. Tourism Management, 2001, 22(6):607-616.

[6] Iii J G M. Service recovery's influence on consumer satisfaction, positive word-of-mouth, and purchase intentions[J]. Journal of Business Research, 2001, 54(1):11-24.

[7] Balaji M S, Jha S, Sengupta A S, et al. Are cynical customers satisfied differently? Role of negative inferred motive and customer participation in service recovery[J]. Journal of Business Research, 2018, 86:109-118.

[8] Weber K, Sparks B A. Social Identity's Impact on Service Recovery Evaluations in Alliances[J]. Annals of Tourism Research, 2006, 33(3):859-863.

[9] Weber K, Sparks B. Service failure and recovery in a strategic airline alliance context: interplay of locus of service failure and social identity.[J]. Journal of Travel \& Tourism Marketing, 2010, 27(6):547-564

[10] Balistreri E, Mcclelland G, Poe G, et al. Can Hypothetical Questions Reveal True Values? A Laboratory Comparison of Dichotomous Choice and Open-Ended Contingent Values with Auction Values[J]. Environmental \& Resource Economics, 2001, 18(3):275-292. 